\title{
USING 5D MODELS AND CBA FOR PLANNING THE FOUNDATIONS AND CONCRETE STRUCTURE STAGES OF A COMPLEX OFFICE BUILDING
}

\author{
Juan C. Suarez ${ }^{1}$, Jaime Zapata ${ }^{2}$, and Xavier Brioso ${ }^{3}$
}

\begin{abstract}
Contractors use diverse methodologies and software that require more working hours just to synchronize all the data related to cost, schedule and quantities, the most widespread methodologies are CPM and BIM models. However, the use CPM does not provide the tools to control the project with the current production status. The use of 5D BIM models (integrated quantities, cost and schedules) and flow lines (scheduling system from the Location Based Management System) are proposed as more effective methods, these allow the contractor to automate and improve their scheduling and controlling processes. These methodologies were implemented in the planning process of the foundations and structure stage of a complex building, then compared to the methods used by the contractor (CPM, 3D and 4D models). Choosing by Advantages (CBA), a system that supports sound decision-making using comparisons among advantages of alternatives, was used to compare the methods mentioned, then a total of three alternatives and eight factors were evaluated by the researchers and contractor. The use of 5D models and flowlines were found to be the best alternative, some factors that stand out are scheduling with an effective Lean Production system, synergy with Earn value reports, and automation in quantities and scheduling.
\end{abstract}

\section{KEYWORDS}

Location-based management, 5D model, choosing by advantages (CBA), production pull, workflow, BIM

\section{INTRODUCTION}

Planning and control methods in the construction industry of Peru tend to be outdated in comparison to the world latest trends, software and tools. There are three methodologies commonly adopted by contractors: (1) The Last Planner System (LPS), which is highly valued in the industry. (2) Building Information Modeling (BIM), which is an invaluable process enabler for modern architecture, engineering, and construction (AEC) (Sacks et al., 2018); with this technology, accurate virtual models of a building are constructed

1 Research Assistant, GETEC Research Group, Department of Engineering, Pontifical Catholic University of Peru (PUCP). juanc.suarez@pucp.edu.pe, orcid.org/0000-0003-1433-7766

2 Lecturer, GETEC Research Group, Department of Engineering, PUCP, ifzapata@pucp.pe, orcid.org/0000-0001-7662-8329

3 Professor, GETEC Research Group, Department of Engineering, PUCP, xbrioso@pucp.edu.pe, orcid.org/0000-0002-0174-0241 
digitally (Sacks et al., 2018). BIM is being rapidly adopted in the Peruvian industry, a study conducted in 2017 showed that 1 out of 4 building projects in Peru used BIM (Murguia, 2018), and this is commonly used to improve the visualization, automate the QTO (quantity take-off) process and to identify incompatibilities. (3) And, the Critical path method (CPM), which is an activity-based system for planning. The vast majority of projects are contractually managed with CPM master schedules with multiple sectional completion dates (Olivieri et al. 2016), and this method is mentioned as a contractual tool in the Peruvian government contracting laws (Brioso et al., 2016).

Although the CPM is commonly used as a schedule and control tool, there are several critics to its application for controlling production. The main critic is that the schedulers can only react when a deviation to the critical path has occurred (Seppänen, 2017). Moreover, the construction stage implies lots of changes and uncertain events that are detrimental to the planned milestones, this results in a PUSH control type that seeks to achieve the planned dates without taking into account the actual production status (Seppänen, 2009). The method does not allow the inclusion of tools for considering production rates. Thus, the downsides of the method are: (i) not focusing on the workflow, (ii) neglecting production rates, (iii) omitting the work disparity in locations, (iv) demoting resource management, and (v) inefficient on repetitive projects (Arditi et al., 2002; Olivieri et al., 2018), all of which can be sum up as a lack of synergy between the bases of the CPM and the Lean Construction philosophy. Finally, in relation to the TFV theory of production (Transformation-Flow-Value generation), a research's case of study from the early 2000s revealed that contemporary construction subscribes only to the transformation view of production (Koskela, 2000).

Despite the above mentioned, contractors usually use the CPM with some LPS and BIM tools for planning and controlling the schedules and costs of their projects. This overview implies a lot of time and effort made by engineers to obtain the outputs and lots of fundamental details missed for the daily decision making of the managers. The reason of this is the disconnected process of the scheduling and cost estimation process, not only in the synergy of their basis (e.g. lack of synergy between CPM and LPS) but also in the software used (many software required at the same time for these three methods).

For the mentioned downsides in the planning and control process, methodologies like nD BIM models (4D and 5D) and Location Based Management System (LBMS) are recommended. According to Sacks et al. (2018), "a 4D model is a time-dependent view of a BIM model in which objects are associated with activities in a construction plan" and "A 5D model is a cost-dependent view of a BIM model in which budget line items are associated with specific measurable features of model objects." The aim is to link budget items with model objects, so that future costs can be forecast, and actual costs can be monitored (Sacks et al. 2018). The Location-Based Management System (LBMS) has been developed as an improved algorithm of the CPM that uses the concepts of locations and tasks flowing through locations to augment the traditional CPM, enabling a continuous workflow and aiming Lean goals, like increasing productivity and decreasing waste (Seppänen, 2009). The LBMS is considered a technical system, that, in sum, transforms quantities in locations, determines reliable durations based on productivity information, makes buffers explicit, and alarms of future production problems based on its forecasts (Kenley \& Seppänen 2010), in addition, the LBMS uses flowlines as a scheduling tool. The complexity of the schedules can be greatly reduced by using locations as basic units of information, instead of using activities that can be repeated and generate lots of logic relations that will not be understandable (Kenley, 2005). A study 
that compares the use of integrated 5D and location-based planning system (in a hospital project) to the traditional constructability, estimating and scheduling processes showed that more constructability issues were identified (over 200) in an integrated 5D system in comparison to the traditional system, and the location-based scheduling enabled the planning of continuous work for subcontractors while compressing the duration of Foundation phase by six weeks (Kala et al., 2010).

The main advantage of using the LBMS is its synergy with Lean objectives and BIM. Most of this synergy has been summarized in software that automates many scheduling and QTO processes, and, also, allows the contractors to have all the details needed for their reports and daily decision making. So, instead of using the traditional Lean-CPMBIM process, that are supported by many unconnected software working at the same time and giving different outputs (e.g. spreadsheets to implement Last Planner tools, 3D modelling software, CPM scheduling software, 4D modelling software), the LeanLBMS-BIM simplifies this overview into a software for the 3D modelling and 5D model, the last includes all the information related to the model, schedule and cost information.

In order to know which methodology is better to effectively achieve the goals of the contractor, the Choosing by Advantages (CBA) system is used, this supports sound decision-making using comparisons among advantages of alternatives (Arroyo et al. 2013) through evaluating the importance of each advantage. Recently, meetings with stakeholders have been implemented to select the best constructive process using 4D models and CBA (Murguia and Brioso, 2017). Finally, studies that evaluates the use of 5D models have not been conducted in Peru; moreover, the methodology is not known by most contractors. This research shows the benefits of integrated scope-cost-time solution for lean management compared to traditional methods, following a standardize decision-making

\section{RESEARCH METHOD}

This research aims to elaborate a 5D model for planning the foundations and concrete structure stages of a complex office building ( $24 \mathrm{~m} 2$ of constructed area, 3 basements and 3 upper levels) and evaluate its advantages and attributes with a decision-making system (CBA), in comparison to the traditional planning procedure of the contractor. To achieve these objectives, first, a framework for the traditional/proposed tools is drawn. Second, data of the project was collected in the pre-construction phase, including drawings, CPM schedules, contractual milestones, production rates, unit costs, and planned resources. Third, the 5D model was elaborated using a 3D and 5D modelling software. Fourth, interviews to the contractor and construction experts were conducted to determine the factors, criteria, attributes and advantages of planning with a 5D model, in comparison to the traditional 3D and 4D models used by the contractor, the CBA system was used to evaluate the importance of each alternative, the models were exhibited to the contractor and then the researchers incorporated their input for the CBA. For this study, it is considered that the extra cost associated to the use of 5D BIM software is widely compensated by the economic benefits related to the automation and visualization of the CBA matrix. Finally, the results are discussed, recommendations are mentioned, and directions are presented for complementing this research in a construction stage.

The limitation of this research is the use of the methodology in a construction stage, the researchers only had access to the project during the planning stage, and then the results of the $\mathrm{CBA}$ and the 5D model could not be implemented later in the project. Also, only foundations and structural phases were analyzed by the model. 


\section{D MODELS BASED IN LINE FLOWS}

The contractor was using the traditional methods discussed (Lean-CPM-BIM), the researchers suggested the use of LBMS to support LPS and BIM. LPS and LBMS were found to be complementary in the previous researches, where tools as lookaheads and weekly plans can be easily complemented by the LBMS, allowing to show data like forecasts and early warnings. Also, BIM processes were easily complemented by the LBMS, allowing the implementation of 5D models based on flow lines scheduling.

To develop the 5D models, the inputs needed from the contractor were: contractual CPM schedules, milestones, unit prices, drawings, planned crews' performance, and cost and work breakdown structure. The steps to elaborate the 5D model were: 3D modelling (including elements like foundations, soil filling, and four different types of slabs, beams, ramps, stairs, columns and walls). Then, the location breakdown (LBS) of the model was defined taking into account the area of each floor, two levels of hierarchies were considered: middle levels, used to plan the production flow of the structure (e.g. floors that must be completed before moving to the next), and lower levels, used for planning details where only one trade can work effectively (e.g. the daily areas of work) (Kenley \& Seppänen, 2010). The locations were introduced into the model with the following hierarchy: floors (from the basements to the top floor), blocks (A, B, and C, separated by seismic joints) and zones (to distribute the daily work, one zone per day per activity).

The next step is to relocate all the budget and schedule information (including CBS, WBS, unit costs and production rates) from the spreadsheets to one single software that processes all. The model synchronizes costs, quantities, and schedule, then the flow lines scheduling process was conducted considering the following steps:

(1) An overview of the constructive sequence must be approved in order to have an idea of the logical relations between tasks. (2) Given the project conditions, the bottlenecks must be analyzed for each corresponding stage; in the case of study, the readymixed concrete pouring activity was not allowed during the daytime due to traffic restrictions on the perimeter streets, so the activity was executed at night for 5 hours and was considered to be the main bottleneck in the evaluated stages; also, the researchers had considered that the pouring activity does not completely rely in the crews or equipment, instead, it depends, in a major percentage, on the production of the ready-mix concrete plant, the capacity needed in the peak hours and the time that one mixer truck takes from the plant to the site. (3) Then, the bottleneck activities must be adjusted to a production rate or number of crews that allows the completion of the contractual milestones, once that is completed the rest of the activities (lines) have to be balanced with the bottlenecks slope, the software automatically determines how many crews are needed and the durations per activity for the stablished rate. (4) Finally, all the lines must be balanced considering the bottlenecks and milestones, some adjustments can be done by modifying the construction process or improving the productivity rates.

It should be mentioned that the foundations stage had two main bottlenecks, concrete pouring and soil filling process; the last was underestimated in the traditional planning process, but the 5D BIM model enabled the researchers to notice that this activity was critical and the productivity rates were not enough (lots of crews were estimated in the 5D model), so the technique was changed for other more efficient (the number of crews decreased) and the line slope of this activity set the pace for the framework and rebar activities for foundations. Soil filling was considered in the 5D model. 


\section{RESULTS AND SIMULATIONS}

Figure 1 (a) shows the flowlines for all the foundations and concrete structures stages, the schedule includes milestones, activities, number of crews and productivity rates (line slope). Activities are grouped in a higher level in the WBS, Figures 1 (b), (c) and (d) show a detailed schedule for the foundations, basements, and upper levels, respectively.
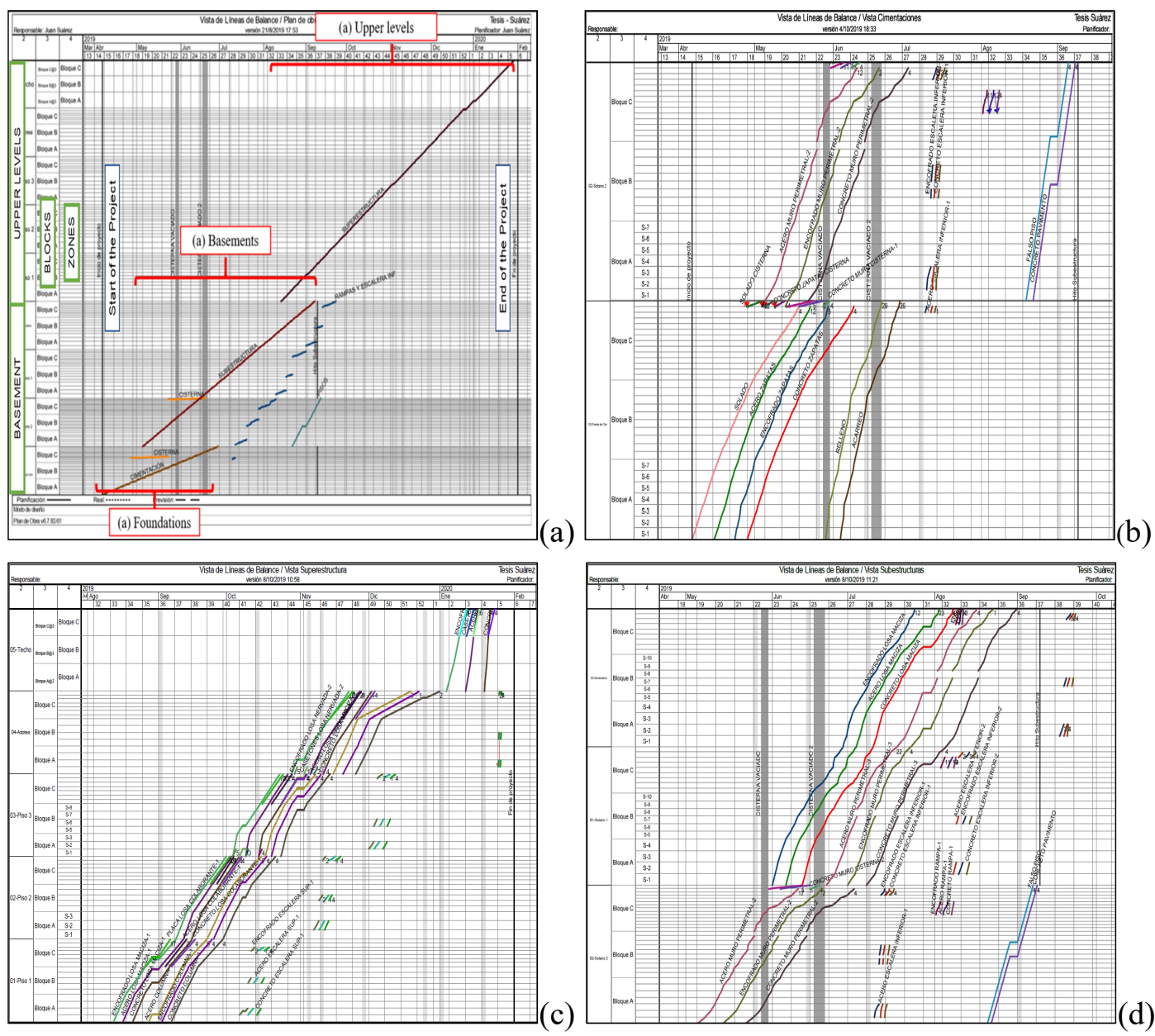

Figure 1: (a) Flowline schedule of foundation and concrete structures. (b) Flow lines for the foundation. (c) Flow lines for the basements. (d) Flow lines for the upper levels

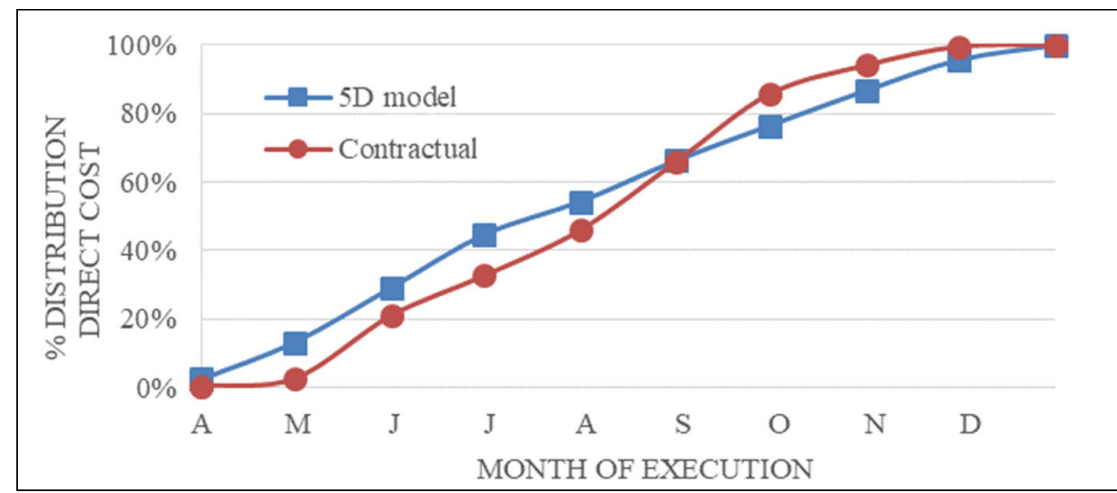

Figure 2: $\mathrm{S}$ curve for the planned value of the 5D model vs contractual $\mathrm{S}$ curve 
Using 5D Models and CBA for Planning the Foundations and Concrete Structure Stages of a Complex Office Building

Planned value is obtained automatically and it's distributed on time, according to the planned flow lines schedule, this is shown in Figure 2, where the planned value obtained by the contractor (using the traditional planning methods) is also shown.

\section{EVALUATING 5D MODELS AND TRADITIONAL METHODS}

The contractor was using a traditional method to plan the project: $3 \mathrm{D}$ models + CPM and 4D models + CPM. 5D models with basis in the LBMS were proposed.

To make an objective decision, the CBA decision-making system was used, as it is a method suggested to make informed decisions when choosing between alternatives, also it is used to make safety design decisions about permanent features of buildings (Karakhan, 2016), this system complements lean practices such as asset-based design and early collaboration, being the Tabular Method of CBA that allows the documentation of construction decisions (Parrish, 2009), as the one is discussed in this paper. The Tabular Method of the CBA applied in the case of study is shown in Table 1, the steps taken to evaluate the alternatives are described below and follows the theoretical statements of previous research (Suhr, 1999; Arroyo et al 2012; Karakhan, 2016).

Alternatives (Step 1): The research considers 3 alternatives to be evaluated for the planning stage of building projects, these are: (1) 3D models + CPM + Lean, (2) 4D models + CPM + Lean, and (3) 5D models + LBMS + Lean. Factors, attributes and advantages criteria (Steps 2 to 5): The contractor and the construction experts' determined initially 10 factors, then reduced it to 8 by grouping similar ones (e.g. "Cost automation and "Earn value report automation").

Factor 1 Plan an effective Lean Production System: The main goal of the contractor was achieving lean goals in their production system; they were aware that Lean objectives will increase the value of the project deliverables. The Criterion for this factor is: Ensuring an effective production system (that involves continuous flows, efficient flows and efficient processes) is better. The attributes are: The Alternative 1 (A1) and 2 (A2) use the Critical path to plan the projects, and the Alternative 3 (A3) uses the LBMS and flowlines for planning the schedule, note that the least preferred attributes are underlined and will be used as comparison points to describe advantages (Arroyo et al, 2013) in Table 1. The advantage of A3 is that it ensures continuous flows with the logic between lines (tasks), and ensures efficient flows by balancing all the tasks with the production rate demanded by the bottleneck and the contractual milestones; finally, it also ensures efficient processes by adjusting the number of crews or rates to optimize the planned schedule. The A2 and A3 only ensures continuous flow within the activities using the logic relations between them and the determined critical path.

Factor 2 Sinergy with Earn Value reports: The contractors use reports based on the planned value, earn value and actual costs, they also use indexes for earn value reports. These reports and information are the most important in the planning and control department of the project, but the contractor had identified that the elaboration of these reports takes a lot of time in their current methodologies and the details permitted are limited to a point that the methods do not allow to make objective decisions. So, the criterion for this factor is: Less time spent in the elaboration with more possibility of detail is better. The attributes are: A1 uses spreadsheets to integrate all the information coming from different software and reports (3D software, CPM software and daily production reports); A2 uses spreadsheets to integrate the costs data, then the quantities and schedules are automatically synchronized 3D and CPM software; and $\mathrm{A} 3$ uses the 5D models to store and process all the information referring to costs, schedule and quantities; also the 
Table 1: CBA Analysis

\begin{tabular}{|c|c|c|c|c|c|c|c|c|c|c|c|c|c|c|c|c|c|}
\hline 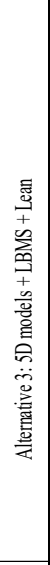 & 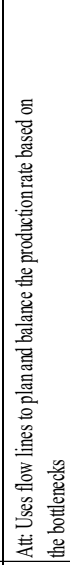 & 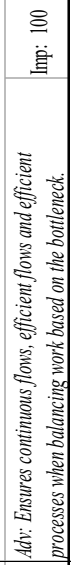 & 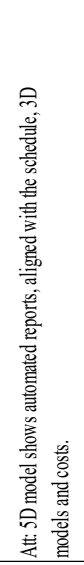 & 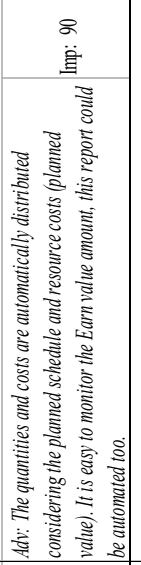 & 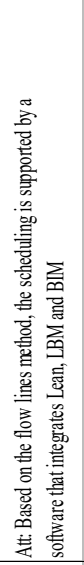 & 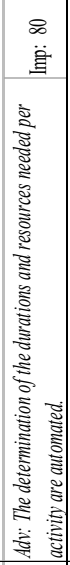 & 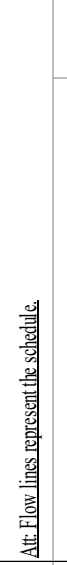 & 姜 & 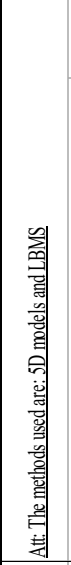 & 妾 & 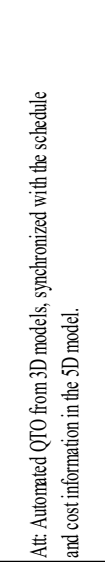 & 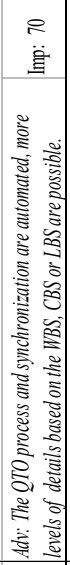 & 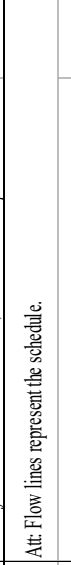 & 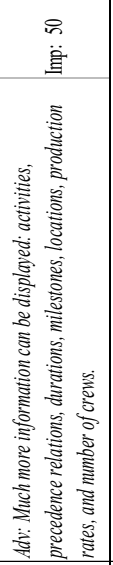 & 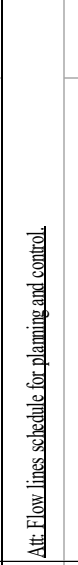 & 妾 & ్ㅣ \\
\hline \multirow[b]{2}{*}{ 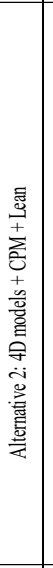 } & & 兽 & & $\begin{array}{l}\text { o } \\
\text { i. }\end{array}$ & & 兽 & & $\begin{array}{l}\infty \\
\text { क } \\
\text { 首 }\end{array}$ & & $\begin{array}{l}\text { n } \\
\text { 首 }\end{array}$ & & $\begin{array}{l}\text { o } \\
\text { 宝 }\end{array}$ & & 音 & & $\begin{array}{l}\text { ह } \\
\text { 宝 }\end{array}$ & \\
\hline & 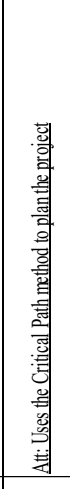 & 童 & 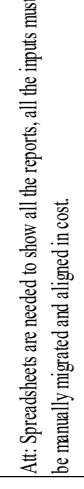 & 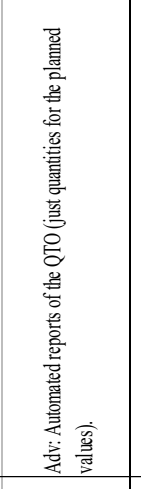 & 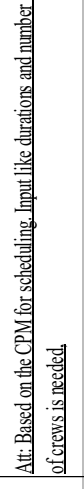 & 妾 & 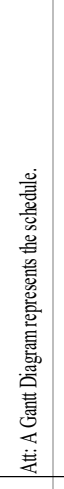 & 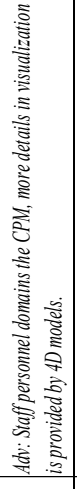 & 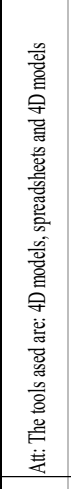 & 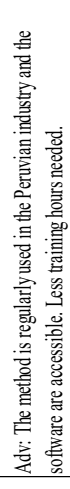 & 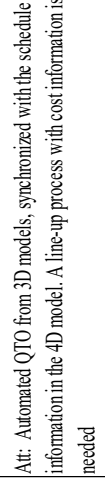 & 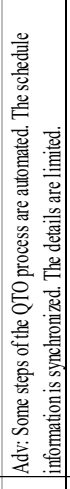 & 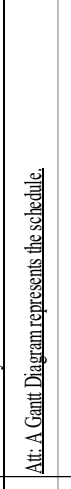 & $\frac{8}{4}$ & 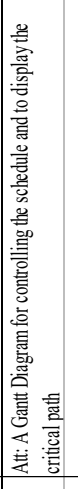 & 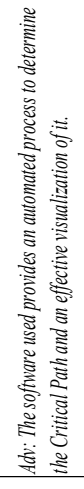 & \& \\
\hline \multirow[b]{2}{*}{ 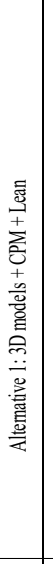 } & \multirow[b]{2}{*}{ 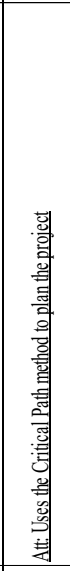 } & \multirow[b]{2}{*}{ 妾 } & \multirow[b]{2}{*}{ 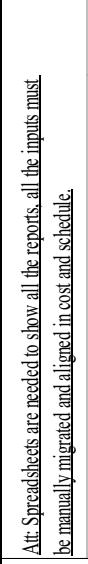 } & \multirow[b]{2}{*}{ 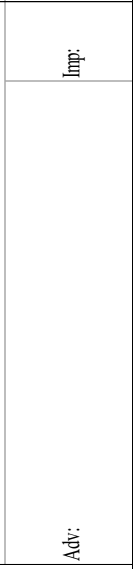 } & \multirow[b]{2}{*}{ 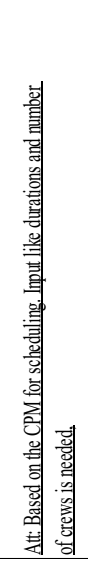 } & \multirow[t]{2}{*}{ 产 } & \multirow[b]{2}{*}{ 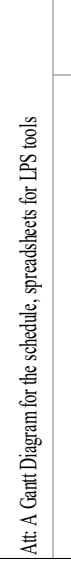 } & $\begin{array}{l}8 \\
\text { 兽 }\end{array}$ & \multirow[b]{2}{*}{ 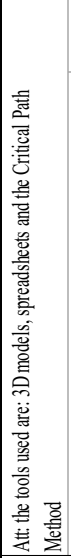 } & $\begin{array}{l}\infty \\
\infty \\
\text { 宝 }\end{array}$ & \multirow[b]{2}{*}{ 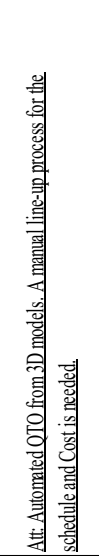 } & \multirow[b]{2}{*}{ 亲 } & \multirow[b]{2}{*}{ | } & 产 & \multirow[b]{2}{*}{ 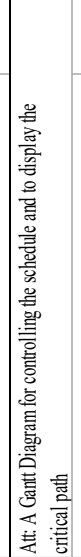 } & 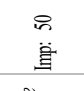 & \multirow[b]{2}{*}{$\Xi$} \\
\hline & & & & & & & & 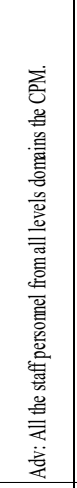 & & 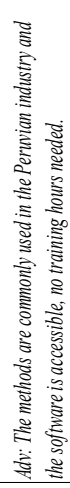 & & & & 妾 & & 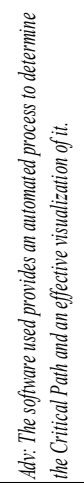 & \\
\hline 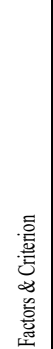 & 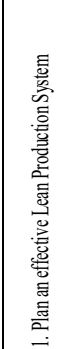 & 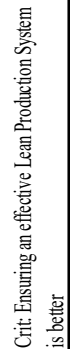 & 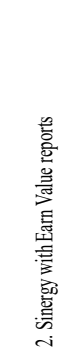 & 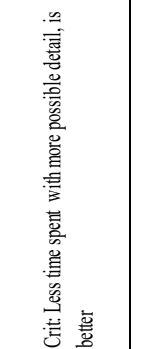 & 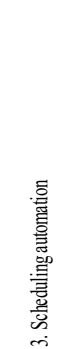 & 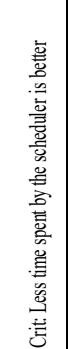 & 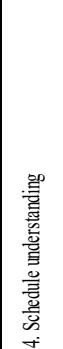 &  & 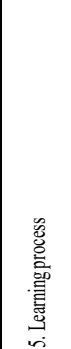 & 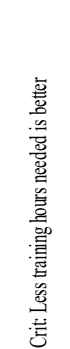 & 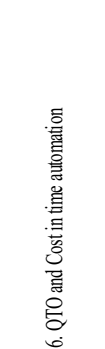 & 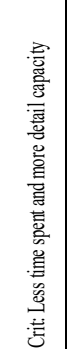 & 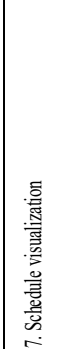 & 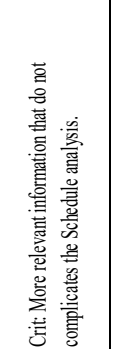 & 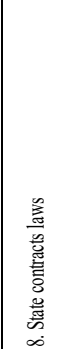 & 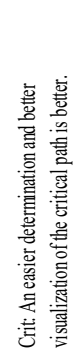 & 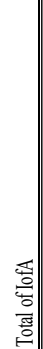 \\
\hline
\end{tabular}


earned value can be tracked in the same software. The advantage of A2 is that the quantities of the planned value are automatically synchronized, but in the case of A3, the quantities and costs of the planned and earn value are automatically synchronized, then reports are automated. Also, it is easy to monitor using lean tools in the software.

Factor 3 Scheduling automation: The contractor is looking for new tools that allow (the engineers) to spend less time in the elaboration of the schedules, especially for the weekly meetings, in which they seek the possibility of analysing the objective effects of current production status in later stages. Moreover, the contractor wants scheduling tools that automate the calculation of critical information for the decision making, like durations, productivity rates needed or resources (e.g. increase the number of crews). The criterion is: Less time spent by schedulers, to determine key information needed, is better. The attributes are: A1 uses the CPM for scheduling, input like number of crews and durations is needed, the rest must be specified manually; the A2 also uses CPM, the difference is that the model is synchronized with the schedule, but the information about durations and number of crews has to be manually specified too (same as A1); the A3 uses flow lines as a scheduling method, and the software that supports it is aligned with the LBMS, Lean and BIM. The advantage of A3 is the automated calculation of the duration and number of crews needed for the production assigned to the tasks considered as bottlenecks, assuming that the production rates are specified by working unit and activity; the A2 and A1 also have some level of automation but is based in the fact that the duration and number of crews have been previously determined.

Factor 4 Schedule understanding: The authors and contractor considers that the capacity of the engineers to understand the proposed system is an essential factor to consider since the system will be used weekly in front of the managers of each area. The criterion is: Better understanding from the contractor's engineers is demanded, this understanding creates an effective environment where all can effectively communicate the variables and outputs, so more participation and ideas are expected. The attributes are A1 presents the schedules using Gant Diagrams, LPS tools using spreadsheets, and drawings using 3D models; A2 differs by using a 4D software to show the Gantt diagram integrated to the 3D model, the planned activities can be shown in a $3 \mathrm{D}$ sequence. The advantage of A1 and A2 is that every staff personnel knows how the CPM works and domains its limitations. In addition, the A2 allows the understanding of the planned schedule with its synchronization with 3D models. The A3 had no advantages for this criterion, the reason is that, even though this alternative was considered as the best technical tool to visualize the schedules (flows between tasks, rate of productions, milestones and durations are effectively pictured in the flow lines), the contractors and subcontractors are used to manage and take decisions using the critical path established, For the A3 the critical path is hardly noticeable; moreover, if many task are dependent on many precedents or successors within the flowlines, these dependencies are missed (even if the flow between tasks is effectively shown).

Factor 5 Learning process: The contractors consider that the methodology selected needs to be presented to the staff, not only to the ones in the field, but also to the staff in their central offices; the subcontractors training is also considered because they will be guided by the same procedures. The process will take effort and time from lots of engineers working in several areas and management positions. The criterion set by the contractor is: Less training hours needed is better. The attributes are A1 uses spreadsheets, $3 \mathrm{D}$ models and CPM as tools and methods; the A2 uses 4D models and spreadsheets; finally, the A3 uses 5D models. The advantages of the A1 and A2 is the common use of 
the methods and software; in the case of A1, no training hours will be needed because the methods and software are basic knowledge in the market, for the A2 just a few hours will be needed for allowing the use of the 4D software. The disadvantage of the A3 is the number of hours needed from the staff to teach them about the LBMS, the 5D software and the synergy of the LBMS with the LPS and BIM.

Factor 6 QTO and Cost in time automation: The researchers consider that contractors' procedures can be highly optimized, requiring less personnel needed for tedious processes as the QTO and distribution of quantities in the scheduled time. The criterion set by the researchers is: Less time spent, and more detail capability is better. The attributes are: The A1 automates the QTO process using 3D models for the quantifiable items, a manual lineup process must be considered to align and process the schedule and cost information from other software; the A2 is similar to the A1 but the line-up process is automated for the schedule information; finally, the A3 has an automated QTO and line-up process, all the information regarding costs, schedule and quantities is automatically synchronized. The advantage of the A3 is that the QTO and synchronization processes are automated thanks to the 5D model, the model allows lots of details (with minimal effort) in the CBS, WBS and LBS (location breakdown structure); the A2 has most of its QTO process automated, quantifications are synchronized with the schedule information, and the detail capacity is limited, if more detail is needed, then many hours will be required to achieve it. The A1 and A2 involves a lot of software (one per output needed) and synchronization processes, this translates into many working hours and effort.

Factor 7 Schedule visualization: The researchers consider that the schedules and methods used by the contractor limit the capacity of information that is needed in the visualization for the decision making in the weekly meetings. The criterion is: More relevant information (for the decision making) in the schedule that will not complicate the analysis, is better. The attributes are: A1 and A2 use Gantt diagrams to visualize the schedule, information like milestones, tasks, durations and precedence logics is presented; the A3 presents the schedule with the flowlines method, which involves information as activities, logics, durations, milestones, slopes of tasks, locations and number of crews. The advantage of the A3 is that this schedule can show more (9 in total) key tools for the decision making, without compromising the visualization of the schedule, it is easier to read in comparison to the Gantt diagram, considering the level of detail; it must be highlighted that locations and slopes (representing production rates) are key elements that are shown at its simplest way, moreover, it can be combined with the actual performance and forecast schedule; A2 allows the scheduler to see basic elements (4) but the addition of more detail (like locations per activity) is detrimental for the visualization, also key information is missing for decision-making, like the actual production rates.

Factor 8: Governmental contract laws, the contractor wants its procedures to be in alignment with the tools that the government considers for controlling projects, given the fact that the contractor's business model is focused on executing buildings for governmental entities. The criterion is: An easier determination and better visualization of the critical path is better. The attributes are: A1 and A2 use Gantt diagrams for controlling the schedule and A3 uses the flowlines schedule for planning and control. The advantage of A1 and A2 is that the schedule control is mainly based on a CPM basis, so the evidence for some delay are represented by this methodology, from which the governmental entities evaluates the contractors' performance. The advantage of A3 is that the Gantt diagram is used as a complement, but the controlling phase is based on the LBMS and the governmental entities do not have knowledge interpreting this results nor 
Using 5D Models and CBA for Planning the Foundations and Concrete Structure Stages

of a Complex Office Building

controlling the performance by them, in the end extra work will be elaborated to present the contractors performance evidence based on the critical path control.

\section{DISCUSSION}

The research presented mention some flaws in the use of CPM, then the case of study showed the lack of integration when using different methodologies and tools for planning and reporting, for example when adopting 3D and 4D models, this led to more working hours for the engineers. However, previous research discussed the 5D models, which have advantages in the synchronisation process, and its application with the LBMS in a case of study, where location-based scheduling enabled the planning of continuous work for subcontractors. Then, the 5D BIM model and the location-based schedule were implemented into the planning stage of a complex building, as a parallel method that complemented the traditional CPM methodology and optimized the contractors QTO process and reporting tools. The CBA system was used to compare the 5D models to the traditional methods and tools used by the contractor.

In the CBA analysis, it was determined that the 5D models with location-based planning system is the alternative with the highest importance of advantages for the comparison of 8 different factors that were critical for the contractor goals. It was observed that this combined methodologies represented the best alternative for:

(1) Planning an effective Lean Production system, where continuous flows were ensured by identifying the bottleneck of the construction stage (in each medium level location: floors), efficient flows were ensured by aligning the slope of each line (in the flowline schedule) guided by the bottleneck and milestones, and efficient processes were ensured when optimizing the construction processes and resources needed. (2) Reporting the baselines of the optimized schedule automatically and having the capacity of showing more levels of details in relation to cost, work or location breakdown structure. (3) Automation in the QTO process, determination of duration and resources like number of crews (guided by the bottlenecks of each locations mentioned) and details in schedule and cost reports.

In this case of study two main bottlenecks were observed: (1) the ready-mix concrete pouring process which was limited by time (restrictions of working the day shifts) and resources (the concrete provider had limited production rates and mixers for the night shift). (2) The soil filling process which had underestimated resources for the production needed and reduced spaces for working, this was needed to complete the first ramps and flooring.

The reports obtained by the traditional model were compared to the reports from the 5D model, the results showed that the traditional estimations (parametric and 2D) carried out by experienced engineers lead to a total direct cost which had a minimum difference (less than 1\%) when comparing it to the direct cost obtained by the 5D model. The difference that stands out is the distribution of the curve from the traditional estimation (red line in Figure 2), which slope is smoothed at the beginning and its inclination is compensated in the final months, where more resources are demanded.

\section{CONCLUSION}

5D models can synchronize different levels of information and details for the main definitions of the project (schedule, costs and quantities), these detail levels are more than 
enough for the requirements of the reports. The synchronization makes automation possible, so the information of quantitates-cost-resources-activities is linked.

From the CBA analysis, it is concluded that the use of 5D models with location-based planning methods are the preferred alternative among the other methodologies used by the contractor for planning the foundations and structural stage in a complex building. This method stands out for allowing to plan an effective Lean Production System guided by productivity demanded by bottlenecks and milestones; automate the earn value reports for planning (and other cost reports with resource details), synchronizing the schedule (which has been planned ensuring continuous flows, efficient flows and efficient processes) with the 3D model and cost information; allowing the automated calculation of durations, resources needed, quantities from 3D models, costs per period and (in the construction stage) interferences in the planned process; and, finally, allowing the development of schedules and reports with much greater detail (in comparison to the traditional methods) and far fewer working hours required (to develop this reports/schedules) with better visualization for the daily decision making.

The 5D planning model allowed the determination of durations and resources needed (based on an effective Lean Production System), and the identification of underestimations in tasks, where more resources than initially planned were required, an example that stands out was the soil filling activity which was critical and the initial construction method implied the use of a great number of resources. Also, it gives the basis for controlling the project, enabling the earned value and productivity monitoring, this facilitates the early warning alerts that shows whenever some future items are compromised, considering the actual status of production; the current methods used by the contractor are designed just for scheduling assuming initial conditions that, if they change (and they will), it leads to an out-of-date schedule report that controls production by the key milestones, without taking into account the resource adjustments (for the milestones and bottleneck activities) and actual conditions of production.

The 3D model represented an automation of the quantity take-off that had almost the same precision of the manual estimation (parametric + manual from 2D drawings), but this false "accuracy" of the manual estimation may not be precise, it allows to be close enough for the final results but fails delivering the accuracy of the cost components budget, where some were overestimated, to ensure the profit of the contractor, and others were underestimated, because of quantification mistakes.

Finally, the conclusions and methodologies developed in this research are complementary to the reports and procedures used by the contractor, so the methods and models can be applicable for building construction contractors with non-repetitive or repetitive stories. Future researches should develop the application of the 5D models and location-based planning methods in the construction stage to identify the benefits of early warnings.

\section{REFERENCES}

Arditi, D., Tokdemir, O.B. and Suh, K. 2002. "Challenges in line-of-balance scheduling." J. Construction Engineering and Management, 128 (6) 545-556.

Arroyo, P., Tommelein, I., Ballard, G. 2013. "Using 'choosing by advantages' to select ceiling tile from a global sustainable perspective." Proc. $21^{\text {st }}$ Ann. Conf. Int. Group for Lean Constr., pp. 309-318. Fortaleza, Brazil.

Ballard, G. and Tommelein, I. 2016. Current Process Benchmark for the Last Planner System. p2sl.berkeley.edu, University California, Berkeley, USA. 
Using 5D Models and CBA for Planning the Foundations and Concrete Structure Stages of a Complex Office Building

Brioso, X., Humero, A., and Calampa, S. 2016. "Comparing point-to-point precedence relations and location-based management system in last planner system: A housing project of highly repetitive processes case study." Procedia Engineering, pp. 12-19.

Frandson, A., Seppänen, O. and Tommelein, I. 201). "Comparison Between Location Based Management and Takt Time Planning." O. Seppänen, V.A. González, and P. Arroyo (eds.) Proc. 23rd Ann. Conf. Int. Group for Lean Constr., Perth, Australia.

Gidado, K.I. 1996. "Project complexity: The focal point of construction production planning." Construction Management and Economics, 14 (3) 213-225.

Kala, T., Seppänen, O., y Stein, C., 2010. "Using an integrated 5D y location-based planning system in a large hospital construction project." Lean Constr. J., 102-112.

Karakhan, A., Gambatese, J., and Rajendran, S. 2016. "Application of Choosing By Advantages Decision-Making System to Select Fall-Protection Measures." Proc. $24^{\text {th }}$ Ann. Conf. Int. Group for Lean Constr., Boston, MA, USA, sect.11 pp. 3342.

Kenley, R. (2005). "Dispelling the complexity myth: founding lean construction on location-based planning." Proc. $13^{\text {th }}$ Ann. Conf. Int. Group for Lean Constr., Sydney.

Kenley, R. and Seppänen, O. 2010. Location-based Management for Construction Planning, scheduling and control. Spon Press. London and New York.

Koskela, Lauri. 2000. An exploration towards a production theory and its application to construction. Espoo, VTT Building Technology. 296 p. VTT Publications; 408.

Murguia, D., Brioso, X. and Pimentel, A. (2016). "Applying lean techniques to improve performance in the finishing phase of a residential building." Proc. 24 ${ }^{\text {th }}$ Ann. Conf. Int. Group for Lean Constr., Boston, MA, USA, pp. 43-52.

Murguia, D. and Brioso, X. (2017). "Using Choosing by Advantages and 4D Models to Select the Best Construction-Flow Option in a Residential Building." Procedia Engineering, 196, pp. 470-477.

Murguia, D. 2018. "Primer Estudio de Adopción BIM en proyectos de edificación en Lima y Callao 2017.” Pontificia Universidad Católica del Perú. Lima, Perú.

Olivieri, H., Seppänen, O. and Granja, A. 2016. "Integrating LBMS, LPS and CPM: A Practical Process." Proc. 24th Ann. Conf. Int. Group for Lean Constr., Boston, MA, USA, pp. 3-12.

Olivieri, H., Seppänen, O. \& Granja, A. 2018. "Improving workflow and resource usage in construction schedules through location-based management system (LBMS)." Construction Management and Economics, pp. 1-16.

Parrish, K., and Tommelein, I.D. 2009. "Making design decisions using choosing by advantages." Proc. $17^{\text {th }}$ Ann. Conf. Int. Group for Lean Constr., Taipei, Taiwan-.

Sacks, R., Eastman, C., Lee, G., Teicholz, P. 2018. BIM Handbook: A Guide to Building Information Modeling for Owners, Designers, Engineers, Contractors, and Facility Managers. Wiley.

Seppänen, O. 2009. Empirical Research on the Success of Production Control in Building Construction Projects. PhD Diss., Helsinki Univ. of Tech., Finland, 187 pp.

Seppänen, O., Ballard, G., Pesonen, S. 2010. "The combination of last planner system and location-based management system." Lean Constr. Spon Press.

Seppänen, O. 2014. "A comparison of takt time and LBMS planning methods." Proc. $22^{\text {nd }}$ Ann. Conf. Int. Group for Lean Constr., Oslo, Norway, pp. 727-738.

Seppänen O. 2018. "Das Location-Based Management-System.” In: Fiedler M. (eds) Lean Construction - Das Managementhandbuch. Springer Gabler, Berlin, Heidelberg

Tommelein, I.D. (2017). "Collaborative Takt Time Planning of Non-Repetitive Work." Proc. $25^{\text {th }}$ Ann. Conf. Int. Group for Lean Constr., Heraklion, Greece, pp. 745-752. 